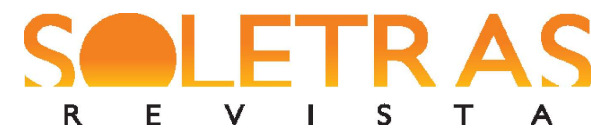

N. 38- 2019.2- LUIZ MANOEL DA SILVA OLIVEIRA MARIA APARECIDA RODRIGUES FONTES SHIRLEY DE SOUZA GOMES CARREIRA

\title{
Poéticas em trânsito: espaços, deslocamentos e temporalidades múltiplas
}

\author{
Luiz Manoel da Silva Oliveira ${ }^{1}$ \\ Maria Aparecida Rodrigues Fontes ${ }^{2}$ \\ Shirley de Souza Gomes Carreira ${ }^{3}$
}

A relação eu/outro constitui um amplo campo de investigação, seja na perspectiva da alteridade como diferença ou no âmbito das representações da diversidade. A par disso, contemporaneamente, as discussões sobre etnia, diáspora, e identidade cultural, além de propiciarem condições de enfrentamento das diferentes formas de opressão e exclusão, subalternidades e assimetrias sociais, acabam também por problematizar as representações do indivíduo, do espaço e do tempo na literatura.

Bertrand Westphal (2007), no ensaio La Géocritique. Réel, fiction, espace (2007), mostra que a tentativa de separar o real da ficção, enquanto espaço físico, é ineficaz, uma vez que a produção de sentido é correlata às atividades da imaginação e representação estética. Hoje, o trabalho dos escritores em "trânsito" é de conectar as diferentes culturas e de criar uma continuidade entre os espaços que são atravessados, uma espécie de continuum entre exterior e interior (o espaço narrado e o espaço social vivido), como a dobra da fita de Möbius. É deste lugar, de valor cultural híbrido e de dimensões temporais diversas, que eles elaboram seus projetos históricos e literários, demonstrando que a cultura como estratégia de sobrevivência é transnacional e traduzível. Transnacional, porque, conforme Homi Bhabha (2001), os discursos póscoloniais estavam enraizados nas histórias específicas do deslocamento cultural. Assim,

\footnotetext{
${ }^{1}$ Doutor em Literatura Comparada (UFRJ); Professor Associado I no DELAC - Departamento de Letras, Artes e Cultura, da UFSJ - Universidade Federal de São João Del-Rei/MG; atualmente, docente permanente e coordenador do PROMEL - Programa de Mestrado em Letras, da UFSJ. Membro do grupo de pesquisa "Poéticas da diversidade". São João Del-Rei, MG, Brasil.E-mail: luizmanoel@ufsj.edu.br.

${ }^{2}$ Doutora em Ciência da Literatura pela Universidade Federal do Rio de Janeiro. Professora/pesquisadora de Literatura portuguesa e Brasileira do DiSLL, Università Degli Studi di Padova. Itália. E-mail: marfonte3@gmail.com,

${ }^{3}$ Doutora em Literatura comparada (UFRJ); Professora Adjunta do Departamento de Letras da Faculdade de Formação de Professores da UERJ e docente permanente do Mestrado em Estudos Literários do PPLIN- UERJ. Líder do grupo de pesquisa "Poéticas da diversidade". Rio de Janeiro, RJ, Brasil. E-mail: shirleysgcarr@gmail.com.
} 


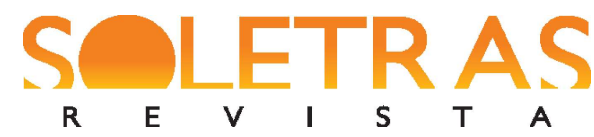

N. 38- 2019.2- LUIZ MANOEL DA SILVA OLIVEIRA MARIA APARECIDA RODRIGUES FONTES SHIRLEY DE SOUZA GOMES CARREIRA

o sujeito em diáspora cria uma forma de espaço "monádico-nomádico" que é um espaço topológico e não topográfico. Estar em movimento delineia também um espaço-limite, onde o interior e o exterior se invertem. Este espaço da torção, da dobra, e da nomadologia é também de tradução de uma língua, étnica e literariamente falando, que se torna um órgão móvel e nômade.

Nesse sentido, também vale evocar alguns pensamentos de Eva Hoffman (1999) em seu ensaio "The New Nomads", quando ela afirma que embora o "exílio" possa ser tomado friamente como um conceito teórico, universal, não podemos desconsiderar uma rede complexa de prismas que subjazem a essa ideia, uma vez que as diferentes circunstâncias determinantes das migrações do indivíduo estão eivadas de implicações políticas, culturais e sociais que terão enormes impactos práticos e psicológicos na sua vida. Contudo, como essa questão é muito complexa, Hoffman afirma também que, pelo fato de a globalização estar determinando trocas e interações culturais com uma aceleração e dinamismo nunca antes vistos, as noções de exílio e terra natal ("home") têm sido o foco constante das discussões teóricas contemporâneas. Uma consequência disso é que "nós sabemos que hoje vivemos em uma aldeia global, embora essa aldeia seja de fato virtual - uma aldeia dependente não de localização ou de raízes fincadas no solo, mas daquilo que os teóricos chamam de desterritorialização - ou seja, o afastamento do conhecimento, das ações, das informações e da identidade de algum lugar físico específico. Em suma, tornamo-nos menos ligados aos espaços e talvez também mais despegados da noção de tempo" (HOFFMAN, 1999, p. 44). Tanto o narrador em trânsito, como os protagonistas dessa poética da diversidade, ao transitar em novos ambientes, se traduzem no espaço no qual se deslocam e se desdobram. Contudo, Bhabha (2001) observa que o tema da diferença cultural e da etnia, ao habitar os interstícios e embora seja um elemento de resistência no processo de transformação social, também é um problema porque ocupa o espaço liminar da tradução, que muitas vezes não é em si traduzível.

A proposta deste número da revista Soletras, portanto, é analisar as relações entre espaço e escritura, considerando as temporalidades diferentes e partindo do pressuposto de que não existe hoje uma linha evidente que separe os espaços imaginados e imateriais, presentes nas obras literárias de autores contemporâneos, 


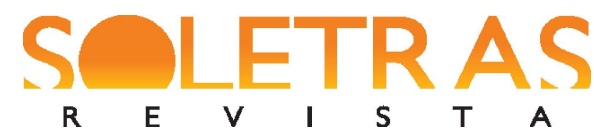

N. 38- 2019.2- LUIZ MANOEL DA SILVA OLIVEIRA

MARIA APARECIDA RODRIGUES FONTES

SHIRLEY DE SOUZA GOMES CARREIRA

sobretudo daqueles em trânsito, porque o espaço na literatura se abre a interrogações que transcendem a análise das relações topográficas. Trata-se, sobretudo, de uma narrativa que conecta o interno e o externo, e uma literatura "em trânsito" que traça linhas itinerantes, mas não indica seus confins, e que mantém relação com outras questões, tais como as atinentes à identidade, gênero e etnia, dentre outras.

$\mathrm{O}$ número apresenta vinte e um artigos e três entrevistas com romancistas contemporâneos. Em "A reescrita obsessiva da infância em dois livros de Salim Miguel: a criação de um espaço autoficcional", Ana Cláudia de Oliveira da Silva reflete sobre a escrita autoficcional de Salim Miguel e a instauração de um pacto ambíguo com o leitor a partir do exame das obras Onze de Biguaçu mais um (1997) e Reinvenção da infância (2011).

Ana Cristina dos Santos, em "Sujeitos femininos desenraizados ou as novas experiências do não pertencimento", discute as novas relações com o espaço que resultam das experiências dos deslocamentos e suas consequências para as personagens femininas de Apenas diez(2006), da escritora uruguaia Marisa Silva Schultze e Pasajeros en tránsito (2013), da escritora chilena Rossana Dresdner, que configuram a chamada segunda geração do exílio, ou seja, de filhos de pais exilados das ditaduras latino-americanas. Ao fazê-lo, busca também verificar de que maneira a perda dos referentes espaciais modificam esses sujeitos femininos desenraizados.

Em "Rui Nunes ao espelho da Europa", Annabela Rita analisa o modo como Rui Nunes equaciona, na sua ficção, as relações entre vida e morte, através da mediação da dor, da doença, da senescência, da História coletiva e da biografia individual.

Partindo dos conceitos de território e desterritorialização, propostos pela filosofia de Gilles Deleuze e Félix Guattari, o artigo de Annita Costa Malufe e Renata Vaz Shimbo- "Deslocamentos contínuos: territórios e línguas em Samuel Beckett”visa a apontar para três principais desterritorializações que seriam responsáveis por uma poética do deslocamento e da errância constantes, que caracterizaria a obra de Beckett: desterritorialização do país de origem, da língua natal e, por fim, da linguagem verbal como um todo.

Em "Sobre rostos e distâncias: deslocamentos nas narrativas bíblicas de Sara e Rebeca", Altamir Celio de Andrade examina as narrativas bíblicas sobre Sara e Rebeca, 


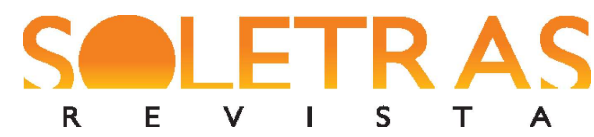

N. 38-2019.2- LUIZ MANOEL DA SILVA OLIVEIRA
MARIA APARECIDA RODRIGUES FONTES
SHIRLEY DE SOUZA GOMES CARREIRA

personagens presentes no Livro do Gênesis, como referenciais para se pensar o deslocamento espacial como indicativo de mudanças internas, tendo em vista conceitos de exílio e deslocamento, utilizados contemporaneamente no contexto dos estudos literários, culturais e filosóficos, sobretudo a partir de Emannuel Lévinas, Stuart Hall e Jean-Luc Nancy.

"Reconstrução dilacerada: memórias de um proscrito", de Aurora Cardoso de Quadros, analisa a associação entre a estética e a vida no exílio de Ferreira Gullar, trazendo ao centro o Poema Sujo, publicado em 1976. Por sua vez, Cláudio Roberto Vieira Braga e Bruno Cardoso abordam a construção discursiva de um imaginário da mobilidade na obra Rakushisha, de Adriana Lisboa, por meio de uma negociação entre as instâncias metafísicas do fluxo e da fixidez.

Em "Uma dolorosa aprendizagem: espaço (d)e escrita em António Lobo Antunes", Denis Leandro Francisco relaciona espaço e escrita nos três livros de estreia do escritor português António Lobo Antunes: Memória de elefante (1979), Os cus de Judas (1979) e Conhecimento do inferno (1980), enquanto que Érica Fernandes Alves e Alba Khrishna Topan analisar a revisão histórica e a busca da identidade indígena na obra Flight (2007), do escritor indígena Sherman Alexie.

Felipe Vale da Silva, no artigo "O gênero excepcional. Apontamentos sobre a recepção de narrativas de escravos nos EUA", focaliza as narrativas de escravos como instrumento de luta contra o sistema escravagista dos EUA, bem como o espectro, da resistência oferecida pelo establishment literário posterior, que negou lugar ao gênero no cânone.

Gabriel Fernandes de Miranda e Maria Conceição Monteiro discutem a construção do espaço em dois romances contemporâneos de língua inglesa, The enigma of arrival e Youth, a partir de uma perspectiva histórica, buscando compreender as formas de diálogo com as figurações tradicionais dos espaços narrados.

Em “The Queer and the Ominous. Lina Meruane's Poetics of 'Degeneration"', Gabriele Bizarri examina a poética de Lina Meruane, em especial à ênfase dada pela autora ao deslocamento e à degeneração.

Gracielle Marques analisa, em seu artigo, algumas microficções do livro Bosque de Ojos: microficciones y otros textos breves (2011), de María Rosa Lojo, de modo a 


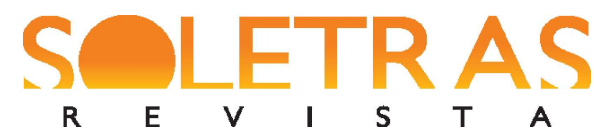

N. 38- 2019.2- LUIZ MANOEL DA SILVA OLIVEIRA

MARIA APARECIDA RODRIGUES FONTES

SHIRLEY DE SOUZA GOMES CARREIRA

estabelecer a relação entre a brevidade e a recriação da memória cindida, reflexo da diáspora galega.

Kelly Viana dos Santos e Sylvia Helena Cyntrão abordam a expressão escrita como tentativa de assimilação e representação de uma nova cultura nos romances Nove noites, de Bernardo Carvalho, e $O$ enteado, de Juan José Saer, enquanto que Luiz Manoel da Silva Oliveira e Shirley de Souza Gomes Carreira analisam o romance $A$ hora da história (2014), de Thrity Umrigar, com base na tríade conceitual migraçõesespecularidade-sororidade, visando ao exame das tensões e interações advindas das relações especulares entre as protagonistas.

Em "Lugares da literatura e os sentidos dos lugares: transnacionalização, deslocamentos e violência em Bernardo Carvalho", Maria Aparecida Fontes busca demonstrar como Bernardo Carvalho, em $O$ filho da mãe, trata das questões relativas ao transnacional na literatura, ao abordar o comportamento das personagens e as suas relações dentro de uma estrutura social deteriorada pelos conflitos e pela violência.

Maura Rossi, por sua vez, em "La maquinaria narrativa de Alberto Méndez ante la entropía del trauma", revisita a obra Los girasoles ciegos", de Méndez, que se everedando pela pós-memória, contribui para o debate transliterário da memória do trauma da Guerra Civil e do Franquismo.

Em "Literatura cabo-verdiana em trânsito", Norma Sueli Rosa Lima examina a literatura cabo-verdiana na representação de sua especificidade crioula em contato com outras culturas, a europeia e a brasileira, na busca de indagar o Outro enquanto contraponto adverso ou de seu próprio reflexo.

Paulo César Silva de Oliveira, em "Errantes, diferentes, desiguais: em torno de Os emigrantes, de W. G. Sebald", propõe uma leitura crítica de Os emigrantes, problematizando as dicotomias estabelecidas na modernidade entre uma promessa de mobilidade contraposta à clausura de um mundo marcado, conforme a acepção de Walter Benjamin, pelo "mal do progresso" inscrito no pesadelo da história.

Em "Bombaim: cidade máxima - ética da autoconstrução na era urbana", Tarso do Amaral de Souza Cruz analisa pontos centrais da obra Bombaim: cidade máxima, do escritor indiano Suketu Mehta, a fim de explicitar como o autor, ao explorar a cidade de Bombaim e os personagens 'extremos' que nela vivem, confecciona uma nova 


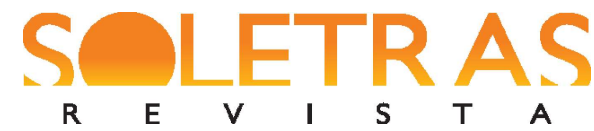

N. 38-2019.2- LUIZ MANOEL DA SILVA OLIVEIRA

MARIA APARECIDA RODRIGUES FONTES

SHIRLEY DE SOUZA GOMES CARREIRA

identidade para a cidade da sua memória e reconfigura o entendimento sobre sua própria identidade de escritor/artista imigrante.

Ximena Antonia Díaz Merino, em "Nueva corónica y buen gobierno i justicia: textualidades, subversión y resistencia en "zonas de contacto"”, analisa a crônica de Felipe Guaman Poma de Ayala, intitulada Nueva corónica y buen gobierno i justicia (1615), considerada uma das primeiras fontes escritas por um indígena que narra sua própria versão da história andina, focalizando as relações assimétricas que ocorrem nas zonas de contato.

O número traz ainda três entrevistas com autores cujas obras encenam a temática das migrações, do processo de aculturação do imigrante e das heranças culturais: Milton Hatoum, Jacques Fux e Marcelo Maluf.

O conjunto de textos que compõe este número perpassa questões inerentes ao deslocamento, à ruptura com o que Marc Augé (1994) denominou "lugar antropológico", ao movimento de reterritorialização e aos diversos modos de aculturação do imigrante, mas aborda também deslocamentos de outra ordem: temporais e discursivos, produzindo uma escrita que se quer migrante e configura um movimento de passagem onde saberes diversos circulam e interagem.

Os organizadores.

\section{Referências}

AUGÉ, Marc. Não-lugares. Trad. Lúcia Muznic. Portugal: Bertrand, 1994.

BHABHA, Homi. Il luogo della cultura. Trad. Antonio Perri. Roma: Meltemi, 2001.

HOFFMAN, Eva. The New Nomads. In: ACIMAN, André, ed. Letters of Transit: reflections on exile, identity, language, and loss. New York: The New York Press/ The New York Public Library, 1999.

WESTPHAL, Bertrand. La Géocritique. Réel, fiction, espace. Paris, Editions de Minuit, 2007. 


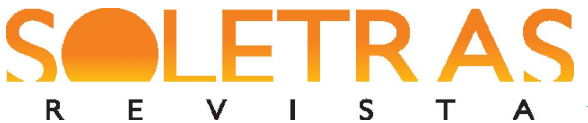

$\begin{array}{llllllll}\mathbf{R} & \mathbf{E} & \mathbf{V} & \mathbf{I} & \mathbf{S} & \mathbf{T} & \mathbf{A} & \text { N. 38-2019.2- LUIZ MANOEL DA SILVA OLIVEIRA }\end{array}$

MARIA APARECIDA RODRIGUES FONTES

SHIRLEY DE SOUZA GOMES CARREIRA 